Article

\title{
Socio-Cultural Sustainability of Private Healthcare Providers in an Indian Slum Setting: A Bottom-of- the-Pyramid Perspective
}

\author{
Federica Angeli ${ }^{1}$, Shila Teresa Ishwardat ${ }^{2}$, Anand Kumar Jaiswal ${ }^{3}$ and Antonio Capaldo ${ }^{4, *(D)}$ \\ 1 Department of Organization Studies, School of Social and Behavioral Sciences, Tilburg University, \\ P.O. Box 901535000 LE Tilburg, The Netherlands; f.angeli@tilburguniversity.edu \\ 2 Department of Health Services Research, Maastricht University, P.O. Box 6166200 MD Maastricht, \\ The Netherlands; s.ishwardat@student.maastrichtuniversity.nl \\ 3 Indian Institute of Management Ahmedabad, Vastrapur, Ahmedabad 380015, India; \\ kjaiswal@iimahd.ernet.in \\ 4 S.E.GEST.A. Department of Management, Catholic University of the Sacred Heart, 00168 Rome, Italy \\ * Correspondence: antonio.capaldo@unicatt.it
}

Received: 22 October 2018; Accepted: 4 December 2018; Published: 10 December 2018

\begin{abstract}
Delivery of affordable healthcare services to communities is a necessary precondition to poverty alleviation. Co-creation approaches to the development of business models in the healthcare industry proved particularly suitable for improving the health-seeking behavior of BOP patients. However, scant research was conducted to understand BOP consumers' decision-making process leading to specific healthcare choices in slum settings, and the relative balance of socio-cultural and socio-economic factors underpinning patients' preferences. This article adopts a mixed-method approach to investigate the determinants of BOP patients' choice between private and public hospitals. Quantitative analysis of a database, composed of 436 patients from five hospitals in Ahmedabad, India, indicates that BOP patients visit a public hospital significantly more than top-of-the-pyramid (TOP) patients. However, no significant difference emerges between BOP and TOP patients for inpatient or outpatient treatments. Qualitative findings based on 21 interviews with BOP consumers from selected slum areas led to the development of a grounded theory model, which highlights the role of aspirational demand of BOP patients toward private healthcare providers. Overall, healthcare provider choice emerges as the outcome of a collective socio-cultural decision-making process, which often assigns preference for private healthcare services because of the higher perceived quality of private providers, while downplaying affordability concerns. Implications for healthcare providers, social entrepreneurs, and policy-makers are discussed.
\end{abstract}

Keywords: choice of healthcare providers; bottom of the pyramid (BOP); emerging markets; grounded theory research; aspirational demand; healthcare business models

\section{Introduction}

There is a major discrepancy in the global economic market; private-sector companies continually seek to reach economically well-off consumers, while simultaneously ignoring a vast majority of the world population, estimated to be over four billion [1]. The base of the pyramid (BOP) concept, first theorized by Prahalad and Hart [2], argues that top-of-the-pyramid (TOP) consumers are the targets for most products and services offered by corporates, while a large part of the BOP population does not have access to goods and services. In its early conceptualization, BOP was defined as the basis of consumers living with a per capita annual income of less than 1500 United States dollars (USD), while TOP consumers (estimated around 75-100 million) live with more than 20,000 USD per 
capita annual income [2]. Currently, BOP includes approximately four billion people living with less than $\$ 9.05$ per day, of which around 2.6 billion individuals earn up to $\$ 2.00$ per day [3-5]. However, it should be noted that, while numerical thresholds vary with contextual conditions and with the idiosyncratic definitions of poverty, BOP commonly identifies those individuals that rely on informal economies and are generally excluded from the capitalistic systems and relevant decision-making processes $[3,6]$.

BOP proponents argue that private-sector involvement in the BOP market would lead to poverty eradication and improvement in the quality of life $[1,2,7]$. This view gained momentum in the last few years, particularly after the United Nations' (UN) release of the 17 Sustainable Development Goals (SDGs) in support of the development agenda 2015-2030. The SDG framework emphasizes how (private) organizations can-and should—contribute to addressing complex societal issues or grand challenges [8], which are rooted at multiple societal levels—social, organizational, and individual. Particularly at the organizational level, the sustainability view redefined performance as a balance between financial, societal, and environmental objectives, also known as the triple-bottom-line (TBL) framework [9-11], which is recognized as providing an alternative to the neoliberal, profit-maximizing paradigm [12].

Promoting health and well-being of disadvantaged communities living at the BOP holds a prominent role in the UN's sustainable development agenda as SDG 3 (Good Health and Well-Being) and is closely related to SDG1 (No Poverty), SDG2 (Zero Hunger), SDG4 (Quality Education), and SDG8 (Decent Work and Economic Growth). Hunger and living in poverty are often due to a lack of formal or appropriate employment, which is associated with low educational levels. Poverty, in turn, is argued to lead to ill health because it prevents people from obtaining the necessary means to ensure good health $[13,14]$. Ill health further adversely affects the financial conditions of the poor, owing to high healthcare costs, loss of wages, and a greater vulnerability to catastrophic illnesses [15]. It is estimated that excessive healthcare payments are one of the main contributors to poverty [16]. Hence, providing access to healthcare directly translates into greater welfare for the BOP population [7]. As a result of the circular relationship between poverty and ill health, the initiative of private healthcare providers in resource-constrained areas could result in a positive change by improving access to healthcare, thereby improving the overall well-being of the deprived population [17]. Private business initiatives in the healthcare sector targeting disadvantaged communities provide ideal examples of TBL organizations or social enterprises, in the sense that they pursue financial sustainability while at the same time improving the socio-economic conditions of the target communities [18].

However, to be able to generate such outcomes, private healthcare providers aiming at targeting BOP patients need innovative, socio-culturally sensitive business models. The health-seeking behavior of BOP consumers presents unique dynamics and is depicted as a complex nexus of, among others, gender, marital status, socio-economic conditions, type of illness, type of available healthcare facility, age, and social role $[19,20]$. The institutional divide, i.e., the distance in social norms, cognitive frames, and normative values between service providers and recipients, is high in the case of BOP consumers [21,22] and particularly exacerbated in the case of healthcare services [23]. Among the BOP population, healthcare needs are often not recognized or ignored because of poor health literacy and fear of social stigma $[24,25]$. Hence, interventions which can educate the BOP population to recognize their health needs, become aware of accessible and affordable solutions, and improve their illness disclosure and health-seeking behavior are needed. Prior work documented how business models that succeed at reaching BOP consumers often display co-creation approaches [26,27], which become even more salient in the healthcare domain [23]. Business models of private healthcare providers need to stem from an in-depth understanding of the health-seeking behavior of target groups, and need to leverage a vital phase of value discovery, which is defined as a "co-creation process through which the healthcare need is identified by the patient and by the organization together" [14,23].

In line with this thread, the present study explores the determinants of BOP patients' choice of public vs. private hospitals in an Indian setting, with the primary aim of providing deeper insight into 
BOP health-seeking behavior and, hence, promote a co-creation approach to the development of new business models aimed at inclusive healthcare delivery. While prior quantitative studies highlighted the relevance of specific provider attributes within BOP individuals' choice of public vs. private providers (e.g., Reference [28]), this study is particularly interested in unveiling the decision-making process leading to specific choices, and the relative balance of socio-cultural and socio-economic factors underpinning health-related decision-making in slum settings. By comparing the perception of BOP consumers toward private and public health providers, this research intends to shed more light on which of the two healthcare delivery models is most appropriate because of its higher match with the socio-cultural expectations of BOP patients, in turn, related to their idiosyncratic conditions. The current study, therefore, pursues an answer to the following question: How do BOP patients choose between public and private healthcare providers?

The research setting of the present study is particularly relevant. The Indian healthcare market is composed of a mix of private and public healthcare providers [29,30], although the private sector is predominant. Public health expenditure in India is among the lowest in the world, with only $1.4 \%$ of the GDP [31], while out-of-pocket expenditure takes up $62.4 \%$ of the total expenditure on health [32]. There is a large need for investments in healthcare, as the current healthcare facilities are deemed insufficient [33]. It was argued that Indian patients prefer private over public healthcare, despite the downsides of high costs and, at times, sub-optimal quality. Peters et al. [34] found that 39\% of private-sector hospitalizations are accounted for by the population in the lowest income quintile, despite their limited financial resources. This choice arguably has the potential to push BOP households further below the poverty line. Therefore, understanding the reasons behind BOP patients' hospital choice is critical to help public healthcare providers improve the perceived quality of their services and, in general, better attract BOP patients to more affordable healthcare providers.

This research aims at advancing existing knowledge about BOP and social entrepreneurship in healthcare, particularly examining the gap between patients' socio-cultural expectations and the organizational models in place. Although a few studies were conducted so far on specific companies delivering healthcare products or services to the BOP [23,35], there was little research on the customers' perspective in relation to the available healthcare providers in BOP settings. This perspective is especially relevant as it can contribute to a better understanding of the needs and health-seeking behavior of the BOP consumers, thus helping bridge the socio-cultural gap between available models and patients' expectations, and inform new, more culturally sensitive and acceptable business models based on co-creation approaches.

The remainder of the article proceeds as follows: Section 2 addresses the theoretical background of the study, by providing an overview of the academic literature related to health-seeking behavior at the BOP, to consumer choice at the BOP, and to recent developments of the BOP managerial paradigm. Section 3 describes the methodological design and the techniques for data collection and analysis used for the qualitative and quantitative phases of this research. Section 4 presents the results and distinguishes between quantitative findings-in the forms of tables and quantitative tests—and qualitative findings—shown using interviewees' quotes and coding process. Section 5 discusses the results in light of previous work and presents the grounded theory model of BOP patients' health-seeking behavior that emerged from our qualitative work. Section 6 illustrates the contribution of our study, together with its academic, managerial, and policy implications. Section 6 also presents the limitations of this research, along with the directions for future research. Finally, Section 7 provides conclusion of our paper.

\section{Background of the Study}

\subsection{Health-Seeking Behavior at the BOP}

The health expenditure of BOP consumers worldwide is estimated at around 3\% of their total expenditures [36]. On average, Indian BOP consumers spend $2.9 \%$ of their household income on 
health, of which the largest part (76\%) is spent on pharmaceuticals. In India, most of the health expenditure is absorbed by the rural BOP population, which amounts to $73 \%$ against $27 \%$ of urban BOP population (Hammond et al., 2007). Because private providers are more expensive than public hospitals, lower-income patients are more likely to seek care at public hospitals, and upper-income patients at private hospitals. Peters et al. [34] found that the ratio of hospitalization in private vs. public healthcare centers was 39:61 for the lowest-income quintile, and 67:33 for the highest-income quintile. Moreover, the authors found that hospitalization in private centers increased with income. At the same time, the private sector accounted for $79 \%$ of the outpatient care for people living below the poverty line in India [34], which suggests a difference in the degree to which BOP vs. TOP patients resort to private or public hospitals for inpatient vs. outpatient healthcare services. Instead, the public sector accounted for the largest share of care in the domain of vaccination $(93 \%)$, prenatal care $(74 \%)$, inpatient bed days (66\%), and inpatient bed days concerning childbirth (63\%) [37].

\subsection{Consumer Choice at the BOP}

In order to understand health-seeking behavior in resource-constrained BOP settings, it is important to consider the consumer behavior of low-income population. Although the behavior and demands of the consumers at the BOP differ depending on the cultural and national traits [38], several factors were identified that can characterize the purchase and consumption behavior of BOP consumers in general. An overview of these factors is presented in Table 1. Prahalad [1] identified mutual trust between consumers and producers as a major factor characterizing BOP consumption. Kuo et al. [38] argued that the BOP consumers strongly rely on social bonds in their purchasing behavior. Some scholars observed that illiteracy, lower levels of education, inaccessibility of information, and socioeconomic conditions prevent BOP consumers from making rational decisions [39]. A recent UN Development Program (UNDP) report reviewing the role of business activities in poverty alleviation highlighted the cognitive impairment caused by poverty, which depletes individuals' self-efficacy, is stressful and distracting, and narrows one's cognitive focus [14]. Furthermore, Prahalad [1] identified a tendency for the BOP population to buy their products locally and in small quantities. He argues that, in order to develop the BOP market, the capacity to consume should be created. Reference [40] identified psychological factors that can influence family purchase decisions at the $\mathrm{BOP}$, such as the family makeup, individual roles, gender, and the roles of family members.

Table 1. Factors influencing choice behavior of bottom-of-the-pyramid (BOP) consumers.

\begin{tabular}{|c|c|c|}
\hline Factors & Implication & Sources \\
\hline Strong social bonds & Trust relationships are key & {$[1,38]$} \\
\hline $\begin{array}{l}\text { Illiteracy, education, information, } \\
\text { socioeconomic conditions }\end{array}$ & $\begin{array}{l}\text { Hinder making rational/well-informed } \\
\text { choice decisions }\end{array}$ & {$[1,39]$} \\
\hline Transportation & Buy locally & {$[1,41,42]$} \\
\hline Long working hours & Need for different opening hours & {$[1]$} \\
\hline Income level & Buy small quantities & {$[1,41]$} \\
\hline Income instability & Buying decisions cannot be deferred & {$[1]$} \\
\hline $\begin{array}{l}\text { Family makeup } \\
\text { Individual roles } \\
\text { Gender } \\
\text { Other family members }\end{array}$ & $\begin{array}{l}\text { Purchase decisions depend on what role } \\
\text { family members take }\end{array}$ & {$[40]$} \\
\hline
\end{tabular}

\subsection{Recent Developments in the BOP Paradigm}

Further factors influencing the choice process of BOP consumers emerged from recent developments in the BOP literature. Several critics of the early BOP approach indeed argued that the mere sale of new products and services to resource-constrained communities, without any further intervention on the socio-economic system in which they are embedded, cannot effectively promote 
long-lasting poverty alleviation, while the consequences could be harmful [43-45]. The exposure of BOP consumers to Westernized lifestyles and related products may induce demand for unnecessary goods that could further deplete the poor's income, in addition to creating socio-cultural dissonance. In the case of sachet-like packaging and sanitary napkins, this may even translate into negative environmental impact [43]. Some viewed the BOP approach as a strategy to legitimize multinational corporation (MNC) expansion along a neo-liberal ideology [43]. Hart and colleagues [46], thus, recognized the limits of the early formulation of the BOP framework, which reflected an ethnocentric conception of development, along with a "white man's burden" approach. This view conceived underdevelopment as a type of denial from basic needs, such as nourishment and safe drinking water, satisfactory housing and clothing, quality healthcare, hygienic living conditions, and power supply. Therefore, reasonable strategies to foster development would aim to address perceived gaps through aid and government intervention, through the direct sale of the perceived missing goods $[46,47]$. However, the drawback of this approach is that it implicitly defined the BOP needs by Western life standards and offered solutions designed according to a Western view of what is suitable and acceptable for BOP consumers, without real involvement of the BOP population and along an imperialistic attitude [43].

In response to these points of criticism, a BOP 2.0 approach was launched [48], which highlights the importance of co-creating solutions with BOP communities, and of involving the BOP not only as mere consumers, but also as business partner and primary participants in the value chain, so as to foster employment, social entrepreneurship, and empowerment. Development was then conceptualized as empowerment through the creation of new skills and capabilities, in line with Amartya Sen's capability approach $[46,49]$. Recent BOP studies, thus, recognized that BOP solutions should primarily be socio-culturally acceptable, leverage needs awareness, and promote accessibility, in addition to meeting affordability constraints [21]. This framework is particularly relevant in the case of healthcare services [23]. In accordance with these recent developments, and in an attempt to contribute to the progress of the BOP scholarship, the present study specifically considers the determinants of the choice of BOP patients between public and private healthcare providers, with a focus on the role played by socio-cultural acceptability in the decision-making process.

\section{Research Design and Methodology}

This study is exploratory in nature and employed a mixed methods research design to examine the decision-making process underlying BOP patients' choice between private and public hospitals. Quantitative research was used to understand which hospital type is preferred by BOP patients, when compared to TOP patients, by analyzing BOP and TOP patient registration data of selected private and public hospitals in Ahmedabad, a city located in the northwest of India, in the state of Gujarat. Qualitative research was used to gather a deeper understanding of the drivers of choice among BOP patients by employing grounded theory methods to find out BOP patients' main concerns and social processes in making consumption choices. Interviews were conducted to capture the motivations, beliefs, and perceptions of the informants. The two research methods offered complementary perspectives on BOP patients' consumer behavior. Indeed, while quantitative methods revealed the behavior of the consumer group regarding its preferences between private and public hospitals, qualitative methods unveiled the individual consumer's choice decision and motivations.

\subsection{Empirical Setting: The Indian Healthcare System}

The research is set in the city of Ahmedabad, in the state of Gujarat, India. The Indian healthcare system consists of both public and private healthcare providers. Public or governmental organizations deliver basic healthcare services in rural locations through primary health centers (PHCs). They also provide a limited level of advanced care in large cities. Private institutions are mainly located in metropolitan and large cities and offer most of the advanced and tertiary care [50]. 
Healthcare delivery in India mostly relies on private and out-of-pocket expenditures. The total healthcare expenditures in the country amounted to 3.89\% of the GDP in 2015, which is remarkably lower than the world average of 9.9\% [51]. Public healthcare spending also decreased since the year 2000 , when it was at $4.19 \%$ of the GDP, following a downward trend that is in contrast with the upward trend of most countries. Public spending accounts for only one-third of total healthcare expenditures, for a total of 1.4\% of the GDP in 2016-2017, against a global average of 6\%, and unlike countries such as China and Brazil where public expenditures cover $56 \%$ and $46 \%$, respectively, of total spending [51]. The National Health Policy of 2017 aims to increase government spending to $2.5 \%$ by 2025 [52].

Gujrat is among the largest and most highly industrialized states in the country, with high per capita income and low unemployment level. Gujarat is also among better performing states with it higher than average performance across select health indicators. As per the health index of National Institution for Transforming India (NITI) Aayog [53], a governmental entity, the state is ranked fourth among the large states in terms of quality of healthcare delivery. The state spent $4.7 \%$ of total budget expenditure on health in 2017-2018 [52], and shows relatively lower levels of out-of-pocket spending on health care, at $63.7 \%$ against $74.4 \%$ for all of India. Only 6.8 households in the state reported catastrophic health expenditures, estimated as health expenses greater than $25 \%$ of usual consumption spending, whereas the figure for all of India is nearly double. Over the years, Gujarat significantly improved the percentage of safe or institutional deliveries, which owes largely to the Chiranjeevi Yojana started in 2005. The state did well in improving infant mortality rate (IMR) and under-five mortality rates (U5MR) in the last decade; IMR decreased from 50 to 34 and U5MR reduced from 61 to 43. However, on immunization and malnutrition, the state's performance is relatively poor [54]. The health outcomes of the state on selected indicators against all of India are provided in Table 2, along with indicators worldwide.

Ahmedabad city has a population of 5.5 million as per the census in 2011 . The city has a large number of public and private hospitals. Among the public hospitals, Civil hospital and VS hospital are the prominent ones, with the former being reported as the largest hospital in Asia [55]. With the state-of-the-art facilities in the private sector, the city also emerged as a hub of medical tourism.

Table 2. Health indicators: India vs. Gujarat; data were sourced from References $[51,56]$.

\begin{tabular}{cccc}
\hline Indicator (Year) & India & Gujarat & World \\
\hline Maternal mortality ratio, per 100,000 live births (2011-2013) & 167 & 112 & 226 \\
Infant mortality rate, per 1000 live births (2015) & 37 & 33 & 31.2 \\
Under-5 mortality rate, per 1000 live births (2014) & 45 & 41 & 43.5 \\
Total fertility rate (2014) & 2.3 & 2.3 & 2.4 \\
\hline
\end{tabular}

\subsection{Quantitative Study}

\subsubsection{Sampling Technique}

The quantitative method of the study aimed at quantitatively examining local patients' health-seeking behavior and preference for private vs. public healthcare providers. The sampling technique aimed to first isolate relevant areas within Ahmedabad city and then collect data on patients' health choices. Three residential areas were selected, namely Wadaj/Vadaj, Kalupur, and Dariapur/Dariyapur, as they host the highest percentage of BOP or TOP inhabitants, based on the latest available statistical outline of the Ahmedabad Municipal Corporation (AMC) [57]. Out of a total of six hospitals located in these areas, three were private, one was private trust, and the remaining two were public hospitals. Two of the three selected private hospitals participated in the "MA Yojana" scheme, a state government's health insurance scheme for people living below the poverty line and for low-income people [58]. All hospitals were approached with a request to provide data for the research. Shardabhen hospital and one anonymous private hospital were unable to provide data on outpatients (OP) due to limitations in their patient registration files. Our sample, therefore, included four hospitals serving the selected areas. Table 3 reports some basic information about our sample hospitals. 
Table 3. Characteristics of the sample hospitals. HCG-Healthcare Global Enterprises Ltd.

\begin{tabular}{lccccc}
\hline Hospital & Private/Public & MA Yojana & Number of Beds & $\begin{array}{c}\text { Number of } \\
\text { Inpatient } \\
\text { Registrations (IP) * }\end{array}$ & $\begin{array}{c}\text { Number of } \\
\text { Outpatient } \\
\text { Registrations (OP) * }\end{array}$ \\
\hline 1. Anonymous & Private & Yes & 290 & 213 & $/$ \\
2. Civil & Public & Yes & 2000 & 1883 & 9987 \\
3. HCG & Private & Yes & 110 & 137 & 222 \\
4. Shardabhen & Public & Yes & 350 & 642 & $/$ \\
5 Jivraj Mehta & Private trust & No & $100-200$ & 165 & 1927 \\
6. Shalby & Private & No & 1700 & 165 & \\
\hline \multicolumn{7}{c}{ * From 2 May to 8 May 2016. }
\end{tabular}

\subsubsection{Data Collection and Measures}

The quantitative data collected concerned patients' income group (BOP vs. TOP), type of hospital visited (private vs. public), and type of treatment sought, distinguishing between inpatient care-hence, requiring hospital admission and stay overnight $-v s$. outpatient care that is provided without an overnight stay. Hospital patient registration data provided information on the type of hospitals and type of treatment. As patient income data were not available, we used the residential area to which each patient belonged, in the form of address, pin code, or ward, as a proxy for the patient's socio-economic status. Out of three selected residential areas (Table 4), Wadaj/Vadaj represented the BOP population, while Kalupur and Dariapur/Dariyapur represented the TOP population. Patient registration data of six hospitals located in Ahmedabad city were collected and analyzed in order to get an understanding of the primary hospital type (public vs. private) visited by BOP vs. TOP patients. Data were collected for the inpatients (IP) and outpatients (OP) registered in the selected hospitals between 2 May and 8 May 2016. This approach led to 15,625 patients included in our dataset, of which 436 were living in the selected BOP and TOP residential areas.

Table 4. Characteristics of the selected residential areas.

\begin{tabular}{cccc}
\hline Area & Slums & Chawls & Total Housing Stock \\
\hline Wadaj & $42.32 \%$ & $7.65 \%$ & 21.633 \\
Kalupur (north and south) & $0.29 \%$ & $0 \%$ & 7.225 \\
Dariapur & $0 \%$ & $0 \%$ & 4.084 \\
\hline
\end{tabular}

Data were sourced from Reference [52].

\subsubsection{Data Analysis}

The collected data were analyzed with descriptive and inferential statistics. Our interest was to test for statistically significant differences between TOP and BOP groups, along two dependent variables. One was the choice between public and private providers and the other between outpatient and inpatient treatment. To this purpose, we conducted a Pearson's chi-square test. Since our dependent variable was categorical, we compared the proportion of the BOP and TOP population visiting public and private hospitals using a 95\% confidence interval. We had independent samples from two populations, and observed numbers of success and failure for both populations greater than 10. Hence, statistical assumptions for using a chi-square test were satisfied.

\subsection{Qualitative Study}

\subsubsection{Selection of Respondents}

Face-to-face, semi-structured interviews were conducted in slum areas of Ahmedabad. We used a saturation-driven sampling approach, where we continued recruiting informants until no new information could be obtained from them $[59,60]$. This method resulted in a sample of 21 informants, with a sample size in line with prior qualitative research work [61-64], particularly with qualitative 
studies conducted in slum settings (e.g., Reference [65]). The informants were recruited using two eligibility criteria. Firstly, they had to live in a slum area; secondly, they, their children, or their parents must have visited a private or a public hospital in the last two years. Informants were initially recruited through personal contacts of one of the co-authors. Then, snowball sampling allowed us to recruit additional informants by requesting the earlier informants to recommend others who met the eligibility criteria. This approach facilitated access and trust formation while eliminating non-response bias. This technique is deemed suitable to ensure theoretical representativeness of the sample and is argued to be particularly effective in "hard-to-reach" settings [60]. The socio-demographic characteristics of our respondents are reported in Table 5.

\subsubsection{Data Collection}

The interviews aimed to get a deep understanding of the perspective of BOP consumers on private and public hospitals, with specific reference to their decision-making process and the perceived socio-cultural gap with the services offered by the hospitals. The interview protocol was developed in consultation with expert practitioners and academics and was piloted with a purposive sample of slum-dwellers before finalizing it. The final interview guide covered questions about the informants' personal situation, their knowledge and opinion of the hospitals, the transportation used, the hospital treatment received, the payment method, and the main drivers of their choices. The interviews were primarily conducted in Hindi, a language spoken in most of India, with the help of two translators who were not only proficient in both English and Hindi, but also had basic knowledge of Gujarati, a language widely spoken in the state of Gujarat, since not all inhabitants of Ahmedabad speak Hindi fluently. Informants were interviewed in their residential area to ensure the atmosphere was comfortable. A modest gift was given to each participant. An activity and experience log was kept for each day of the interviews. The interviews were recorded, and the English translation provided by the translator was transcribed.

\subsubsection{Data Analysis}

The interviews' transcripts were coded through thematic analysis [66,67], which facilitates the tasks of identifying, inferring, and recording patterns and groups of meaning within collected data [67]. The three-step approach suggested by Gioia and colleagues [68] was adopted, which resembles the phases of open and axial coding described earlier by Strauss and Corbin [69]. In the first step, transcripts were coded with the aim of being as adherent as possible to the voices and interpretations of the respondents. This process has the advantage of stimulating the researcher's reflective awareness of her/his own biases and assumptions. Through this first process of open coding, 280 segments were coded along 32 first-order codes.

In the second step, we took a more knowledgeable stance and started abstracting from the empirical to the theoretical level by identifying similarities across first-order codes [68]. This process of axial coding [70] led us to cluster our first-order codes into nine more general and abstract second-order themes. In the last step, similarities across second-order themes were ascertained, which allowed for subsequent grouping of second-order themes into three abstract aggregate dimensions. Throughout the steps, we engaged in a cycling, iterative process of comparison, aggregation, and re-aggregation of concepts, themes, and higher-order categories. Comparisons with constructs drawn from extant literature helped us identify discrepancies and similarities between our findings and prior research, which we, however, kept at a distance, to maintain a state of "semi-ignorance" [68]. Overall, the analytical approach adopted here can be considered as abductive, not entirely informed by prior, preconceived ideas, nor fully guided by empirical findings only [68,71]. 
Table 5. Demographic characteristics of the respondents for the qualitative study. F-female; M-male; INR—Indian rupee.

\begin{tabular}{|c|c|c|c|c|c|c|c|c|c|}
\hline$\#$ & Pseudonym & Age & Gender & Education & Employment & $\begin{array}{l}\text { Household Income } \\
\text { (INR/Month) }\end{array}$ & $\begin{array}{l}\text { Members in } \\
\text { Household }\end{array}$ & Residential Area & $\begin{array}{c}\text { Cost of } \\
\text { Treatment (INR) }\end{array}$ \\
\hline 1 & Kriti & 50 & $\mathrm{~F}$ & None & Security $(\mathrm{H})$ & $8000-10,000$ & 7 & Wadaj & 500 \\
\hline 2 & Shanti & 43 & $\mathrm{~F}$ & 5 th grade & Carpenter $(\mathrm{H})$ & $8000-10,000$ & 7 & Wadaj & 500 \\
\hline 3 & Meeta & 40 & $\mathrm{~F}$ & None & Pani puri $(\mathrm{H})$ & $8000-10,000$ & 6 & Wadaj & 8.000 \\
\hline 4 & Chandan & 40 & M & 10th grade & Carpenter & $8000-10,000$ & 9 & Wadaj & 16,000 (monthly) \\
\hline 5 & Akshay & 36 & M & None & Statue-maker & $<4000$ & 5 & Nehrunagar & $\sim 0-10$ \\
\hline 6 & Abhijit & 40 & $\mathrm{M}$ & None & Peddle & $<4000$ & 6 & Nehrunagar & $\sim 0-10$ \\
\hline 7 & Preeti & 40 & $\mathrm{~F}$ & None & Garbage collector & $8000-10,000$ & 8 & Nehrunagar & 30,000 \\
\hline 8 & Raj & 46 & M & 6 th grade & Driver & $20,000-25,000$ & $\begin{array}{c}4 \\
25 \text { (joint) }\end{array}$ & Ambawadi & \\
\hline 9 & Ramesh & 35 & M & $\begin{array}{l}\text { Senior 2nd } \\
\text { grade }\end{array}$ & Worker & $10,000-12,000$ & 4 & Shahibag & 5000 \\
\hline 10 & Soni & 40 & M & None & Worker & $6000-8000$ & 4 & Shahibag & $\sim 0-10$ \\
\hline 11 & Sweta & 40 & $\mathrm{~F}$ & None & Worker & $<4000$ & 6 & Shahibag & $\sim 0-10$ \\
\hline 12 & Suhash & 33 & $\mathrm{M}$ & 5 th & Bamboo curtains & $10,000-12,000$ & 5 & Isanpur & 3500 \\
\hline 13 & Rita & 60 & $\mathrm{~F}$ & None & Statue-maker & $<4000$ & 1 & Navrangpura & 12,000 \\
\hline 14 & Priyanka & 20 & $\mathrm{~F}$ & None & Trading statues & 15,000 & 10 & Gulabhai Tekra & 16,500 \\
\hline 15 & Meena & 45 & $\mathrm{~F}$ & None & Statue-maker & $15,000-20,000$ & 5 & Gulabhai Tekra & 95,000 \\
\hline 16 & Rajesh & 36 & M & 10th grade & Water-boring & $8000-10,000$ & 5 & Vishala & 82,000 \\
\hline 17 & Rupa & 58 & $\mathrm{~F}$ & 7 th grade & None & $10,000-12,000$ & 11 & Vasna & 30,000 \\
\hline 18 & Jayanti & 46 & $\mathrm{~F}$ & None & None & $4000-6.000$ & 6 & Vasna & 300,000 \\
\hline 19 & Ram & 25 & M & None & Worker & $8000-10,000$ & 5 & Vastrapur & 2000 \\
\hline 20 & Baldev & 40 & M & 10th grade & Worker & $8000-10,000$ & 3 & Vastrapur & $\sim 0-10$ \\
\hline 21 & Jamuna & 51 & $\mathrm{~F}$ & 5th grade & None & None & 3 & Khanpur & $\sim 0-10$ \\
\hline
\end{tabular}




\section{Results}

\subsection{Findings of the Quantitative Study}

\subsubsection{Descriptive Statistics}

An overview of the characteristics of our sample is offered in Table 6. The total number of BOP patients was 246 (56.4\%), of which $10(4.1 \%)$ visited a private hospital, and $236(95.9 \%)$ visited a public hospital. The total number of TOP patients was 190 (43.6\%), of which $26(13.7 \%)$ visited a private hospital, and $164(86.3 \%)$ visited a public hospital. Overall, in our sample, 36 patients visited a private hospital (8.3\%), while the remaining 400 visited a public hospital (91.7\%). Table 6 shows that fewer BOP patients visited private hospitals compared to TOP patients (4.1\% vs. 13.7\%), while more BOP patients than TOP patients visited public hospitals (95.9\% vs. 86.3\%). Furthermore, in the private hospitals, most patients came from the TOP areas (72.2\%), while, in the public hospitals, the majority of patients came from the BOP areas (59\%). These findings suggest that income influences the type of hospital that BOP patients visit, whereby BOP patients emerge as more commonly visiting public hospitals, while TOP patients prefer the services of private hospitals.

Table 6. Cross-tabulation of hospital type and income group. TOP-top of the pyramid.

\begin{tabular}{ccccc}
\hline Income Group & & BOP & TOP & Total \\
\hline \multirow{3}{*}{ Hospital Type } & Count & 10 & 26 & 36 \\
& Expected count & 20.3 & 15.7 & 36 \\
& \% within hospital type & $27.8 \%$ & $72.2 \%$ & $100.0 \%$ \\
& \% within income group & $4.1 \%$ & $13.7 \%$ & $8.3 \%$ \\
& \% of total & $2.3 \%$ & $6.0 \%$ & $8.3 \%$ \\
\hline \multirow{3}{*}{ Public } & Count & 236 & 164 & 400 \\
& Expected count & 225.7 & 174.3 & 400 \\
& \% within hospital type & $59.0 \%$ & $41.0 \%$ & $100.0 \%$ \\
& \% within income group & $95.9 \%$ & $86.3 \%$ & $91.7 \%$ \\
& \% of total & $54.1 \%$ & $37.6 \%$ & $91.7 \%$ \\
\hline Total & Count & 246 & 190 & 436 \\
& Expected count & 246 & 190 & 436 \\
& \% within hospital type & $56.4 \%$ & $43.6 \%$ & $100.0 \%$ \\
& \% within income group & $100.0 \%$ & $100.0 \%$ & $100.0 \%$ \\
& \% of total & $56.4 \%$ & $43.6 \%$ & $100.0 \%$ \\
\hline
\end{tabular}

Note: "count" indicates the occurrences in the sample; "expected count" indicates the expected number of occurrences by chance; "\% within hospital type" indicates the percentage of the income group found in the indicated hospital type; "\% within income group" indicates the percentage of the hospital type being visited by the indicated income group; and "\% of total" indicates the percentage of this variable occurring in the total sample.

\subsubsection{Pearson's Chi-Square Analyses}

Dependent Variable: Private vs. Public

A significant difference was found between income group (BOP vs. TOP) and hospital type (private vs. public) visited by these income groups, with a chi-square $=13.094, p<0.01$, and degrees of freedom $=1$. Here, for BOP and TOP patients visiting public hospitals, $\hat{p}_{1}=0.959$ and $\hat{p}_{2}=0.863$. The $95 \%$ confidence interval (CI) for difference proportions were $(0.04,0.015)$. Since this confidence interval did not contain 0 , we concluded that there was a significant difference in the proportion of BOP and TOP population visiting public hospitals. In other words, we are $95 \%$ confident that at least $4 \%$ more and at most $15 \%$ more BOP patients visited public hospitals compared to TOP patients. Similarly, there is significant difference in the proportion of BOP and TOP population visiting private hospitals, with TOP patients visiting private hospitals more than BOP patients. There is, thus, a significant association between income level and the type of hospital visited. 
Dependent Variable: Inpatient (IP) vs. Outpatient (OP) Treatments

Data were further analyzed to test for a difference between BOP and TOP patients in hospital visits for IP vs. OP treatments. The sample for this test was $n=430$ since two hospitals which did not provide OP data were excluded from the analysis. As shown in Table 7, the total number of BOP patients was $246(57.2 \%)$, of which $34(13.8 \%)$ sought an IP treatment and $212(86.2 \%)$ sought an OP treatment. The total number of BOP patients was $184(42.8 \%)$, of which 19 (10.3\%) sought an IP treatment and $165(89.2 \%)$ sought an OP treatment. The total number of patients who visited a hospital for an IP treatment was 53 (12.3\%), while 377 patients sought an OP treatment $(87.7 \%)$. The Pearson's chi-square test shows no significant difference between BOP and TOP patients in terms of hospital visited (unknown, IP, and OP), with a chi-square $=2.903, p>0.01$, and degrees of freedom $=2$. These findings suggest that there is no association between income and the type of visit. We also compared the proportion of $\mathrm{BOP}$ and TOP population visiting hospitals for IP and OP treatment using a 95\% confidence interval. The results showed no significant difference in the proportion of BOP and TOP populations who visited our sample hospitals for IP vs. OP treatments.

Table 7. Cross-tabulation of type of visit and income group.

\begin{tabular}{|c|c|c|c|c|}
\hline Income Group & & BOP & TOP & Total \\
\hline \multirow{5}{*}{ Unknown } & Count & 0 & 1 & 1 \\
\hline & Expected count & 0.6 & 0.4 & 1 \\
\hline & $\%$ within type of visit & $0.0 \%$ & $100.0 \%$ & $100.0 \%$ \\
\hline & $\%$ within income group & $0.0 \%$ & $0.5 \%$ & $0.2 \%$ \\
\hline & $\%$ of total & $0.0 \%$ & $0.2 \%$ & $0.2 \%$ \\
\hline \multirow{5}{*}{ IP } & Count & 34 & 19 & 53 \\
\hline & Expected count & 30.3 & 22.7 & 53 \\
\hline & $\%$ within type of visit & $64.2 \%$ & $35.8 \%$ & $100.0 \%$ \\
\hline & $\%$ within income group & $13.8 \%$ & $10.3 \%$ & $12.3 \%$ \\
\hline & $\%$ of total & $7.9 \%$ & $4.2 \%$ & $12.1 \%$ \\
\hline \multirow{5}{*}{ OP } & Count & 212 & 165 & 377 \\
\hline & Expected count & 215.2 & 161.8 & 377 \\
\hline & $\%$ within type of visit & $56.2 \%$ & $43.8 \%$ & $100.0 \%$ \\
\hline & $\%$ within income group & $86.2 \%$ & $89.2 \%$ & $87.5 \%$ \\
\hline & $\%$ of total & $49.2 \%$ & $38.3 \%$ & $87.5 \%$ \\
\hline \multirow{5}{*}{ Total } & Count & 246 & 184 & 430 \\
\hline & Expected count & 246 & 184 & 430 \\
\hline & $\%$ within type of visit & $57.2 \%$ & $42.8 \%$ & $100.0 \%$ \\
\hline & $\%$ within income group & $100.0 \%$ & $100.0 \%$ & $100.0 \%$ \\
\hline & $\%$ of total & $57.2 \%$ & $42.8 \%$ & $100.0 \%$ \\
\hline
\end{tabular}

\subsection{Findings of the Qualitative Study}

As described in a preceding section, the systematic coding procedure of the qualitative material led us to identify 32 first-order codes, nine second-order codes, and three main aggregate themes underpinning BOP patients' choice of healthcare provider. We labeled the three main themes as follows: (1) provider choice as a social-cultural process; (2) perceived better quality of private healthcare provision; (3) relative unimportance of affordability concerns. Figure 1 presents the coding tree where the initial 32 first-order codes (left) were then grouped into nine second-order codes and then into three aggregate themes (right). The figure also reports, in brackets, the number of segments retrieved per code. This provides a numerical estimate of the relative importance of the specific code within the transcripts. For example, affordability considerations are twice less frequent than quality considerations, with 62 segments coded for the theme "affordability matters" vs. 121 segments coded for the theme "perceived better quality of private healthcare provision". In terms of saliency of concepts within the respondents' answers, quality emerges as the most important driver for choosing private 
over public, followed by socio-cultural considerations within the close community, then affordability concerns. The presentation of the findings is structured along the three main thematic dimensions, while reference to second-order themes are occasionally made. Pseudonyms are used to protect the respondents' privacy.

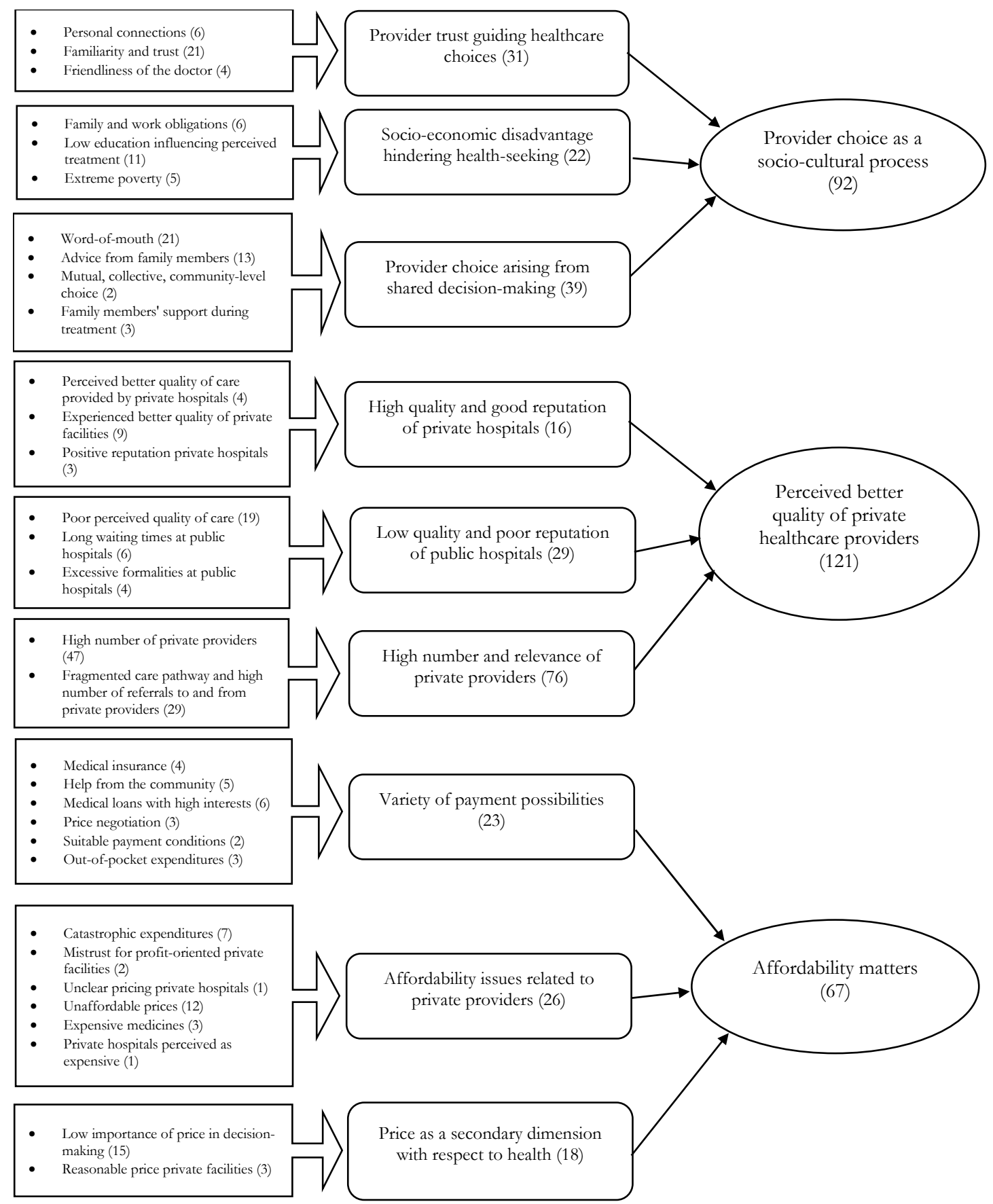

Figure 1. Representation of the coding tree that resulted from the coding process, with first-order codes (left), second-order codes (middle), and aggregate themes (right). In brackets, the indication of the number of segments retrieved per code is shown.

\subsubsection{Provider Choice as a Socio-Cultural Process}

The choice of healthcare provider appears to be deeply influenced by the patients' socio-cultural circumstances at the moment of illness, by the established trust toward specific providers, and by the opinion and experiences of family members, friends, and community-dwellers at large concerning 
healthcare services. Among these socio-cultural circumstances, family obligations hold an important role, as patients living in resource-constrained settings often must restrain from seeking healthcare to avoid heavy repercussions of their absence on their families' livelihood, safety, or order (first-order theme "family and work obligations"). As one respondent told us,

I am the eldest sister of three sisters - all unmarried. So, I have the responsibility of the house, and of the two younger sisters as well. If I go for the operation, if something happens to my life, who will take care of my house and my two younger sisters? I'll have some care when my family problems will come down. At that time, I'll get operated. (Jamuna)

Trust and familiarity toward the hospital and specific physicians emerge as important factors in guiding the choice of healthcare provider. BOP patients report high levels of loyalty toward doctors and institutions, which are triggered by positive personal experiences, or by recounting of family or community members (first-order theme "familiarity and trust"). Also, respondents report a personal connection with healthcare providers as important to cement the feeling of trust (first-order theme "personal connections"). A respondent notes,

So, from childhood days, father and sons, everyone is going to this hospital, and they get cured by the prescribed medicines; now, they have an emotional touch and good experience. Because we are emotional people ... you know. Yeah, so an emotional connection with this hospital. (Abhijit)

Familiarity with the doctor and trust are particularly valuable in the examined setting since people living in poor conditions often feel intimidated by doctors and hospitals. The disadvantaged conditions of BOP patients, their low level of education and, hence, their limited understanding of medical science may instill irrational fears (first-order themes "low level of education influencing perception of care" and "extreme poverty"). For example, one respondent recalled running away from a hospital to avoid treatment that seemed suspicious or too experimental.

Author: So he's scared about the VS hospital because he fears that they will treat him badly.

Translator: Yeah. Not badly, but, ehm, he fears that they want to experiment with his body.

Author: Because he is poor?

Translator: Yeah obviously because he is poor. (Akshay)

It is, therefore, not surprising that healthcare-seeking decisions do not rely only on personal assessments, but also heavily on the opinions and experiences of the community as a whole, in terms of family members, neighborhoods, and kin (second-order theme "provider choice arising from shared decision making", combining first-order themes "word-of-mouth", "advice from family members", "mutual, collective, community-level choice", and "family members' support during treatment". The following excerpt is illustrative of this point:

So, everyone has said that Dr. Umesh is good, his treatment is good. We knew that he is good, we are familiar with him and he is very nice. A strong advantage is that he straightaway starts the treatment because he is familiar with the local people here. So he doesn't always ask to deposit the advance amount first. Everybody really likes him, and he's a specialist for children. Most of the people who go to him get cured by taking the prescribed medicines. (Rupa)

Another important dimension was the doctor's friendliness (first-order theme "friendliness of the doctor"). Several of our respondents noted that private doctors, more often than doctors in public hospitals, tended to show friendliness and familiarity and to establish long-term relationships with the community.

I think the Latesia [private hospital] is good because the doctor doesn't think the patient as a patient, he himself seems like they are my near ones and dear one. The moment I was scared to go for angioplasty because I was in a very bad condition; the doctors said it's curable, think of me as your brother or as 
your father. At that time, I thought that he is not my brother my father but he is like a god for me. Because when I was done with angioplasty, I was perfectly alright, and he was the one who encouraged me and gave all the motivation and support that I was looking for at that point of time. So I have great respect for him. (Jamuna)

Overall, based on word-of-mouth and familiarity, private providers seem to be strongly preferred by BOP patients-a point we return to in the next section. One of our respondents recalled that,

So, they went twice to the government hospital, but their medical problem wasn't cured, so they decided to visit Bhavanbhai [private hospital], because she's very popular, and they don't want to get operated in a government hospital. There, a couple of people died because they believe that most of the people in government hospitals are trainees, they are not the actual doctors. So, they try to keep themselves away; when it comes to the operation, they are scared to get it done at the government hospital. (Preeti)

\subsubsection{Perceived Better Quality of Private Healthcare Provision}

The interviews unanimously and powerfully indicated that private healthcare providers are perceived by BOP patients as offering better-quality services than public ones (121 segments coded on this topic). Several arguments were provided in support of this view, which seemed to be reinforced not only by negative personal experiences associated to public facilities, but also by the unfavorable recounting of neighborhoods, friends, and family members. The association of private hospitals with high-quality care and public hospitals with poor-quality services appears so highly entrenched and institutionalized that hardly any example of divergence from this stance can be found in the interviews. A respondent noted,

I have not visited the GH (government hospital), but everyone has a bad experience there, so I prefer not to go. I prefer private. Because everyone is saying they don't have equipment and personnel, so they have the impression that they will not get proper attention and treatment. (Shanti)

Public hospitals are mainly criticized for their long waiting times, excessive bureaucracy, and unqualified personnel, all of which are perceived to have dreadful consequences on the quality of care delivered (first-order codes "long waiting times at public hospitals" and "excessive formalities at public hospitals"). As an example of the long waiting times and excessive formalities in public hospitals, a respondent mentioned,

My father needed emergency care, and it took around 2-3 $\mathrm{h}$ to actually get the treatment started. I needed to fill up many forms. It took really lot of time for the doctor to attend him. When the doctor came, he just suggested that my father should have gotten a CT scan done first. Now, at the CT scan, there is also a queue, but my father was lying on the stretcher for $2 \mathrm{~h}$. And he was an emergency case. (Raj)

Translator: He's saying that they had to wait for two days outside the hospital to get in. There were a lot of formalities they had to perform...

Author: And they had to sleep outside of the hospital?

Translator: Yes, they had to sleep outside of the hospital, in the street. (Soni)

Also, in terms of quality of diagnosis and treatment, public hospitals are perceived as offering poor quality and conducting wrong diagnoses (first-order code "poor perceived quality of care"). This perception further adds to the feeling of wasting patients' time. One of our respondents recalled,

I went to the Civil Hospital. Once there, initially I was told that I had heart problems and I should go to the heart specialist. When I went to see the heart specialist, he said that I had a problem in the kidney. So, this was the experience at Civil. I went in the morning, and by that time, I wasted so much time that it became afternoon, so I just came back home. (Chandan) 
Because of family obligations and the general fear of healthcare treatments, BOP patients typically delay healthcare-seeking until the ailment reaches a serious, emergency stage. Hence, the delay in receiving treatments and the long waiting times at government hospitals are perceived as particularly negative. Therefore, private hospitals emerge as a much better alternative, given the time-saving aspect and the higher quality associated with private facilities. A respondent mentioned,

So, when we go to the government hospital, we have to stand in a long queue, and then come back home and cook the meals for the family. We can save their time and go to a private hospital and we will get personal attention from the doctors, in the private hospital. In the government hospital, we don't get the proper answers, and nobody is there to attend us. (Kriti)

Given the shortcomings attributed to public facilities, BOP patients associate higher quality with private hospitals and providers (first-order codes "perceived better quality of care provided by private hospitals", "experienced better quality of private facilities", and "positive reputation of private hospitals"). In addition to the much lower waiting times, private hospitals offer BOP patients highly appreciated personal attention and customized care. We realized that, in several cases, seeking private healthcare treatment allowed poor, disadvantaged individuals to temporarily escape from their daily harsh reality and, thus, experience life as a wealthier person. For example, a respondent highlighted,

I enjoyed watching the TV (television) and the facilities which were clean.

... Cleanliness, neat and tidy, because, I mean, we're living in the street and we do not have our own

$T V$ and we enjoy this kind of thing in the hospital. We felt like we're in a hotel.

... We took the general class. And the general class was on the terrace, there were 15 beds. But the cleanliness was good, there was a TV, there was a bathroom. And the treatment was really good, there were nurses visiting every 5-10 min, there were check-ups and everything. (Preeti)

From the respondents' recounting of their care experiences, it also emerged that private hospitals and clinics are in high numbers and easily reachable for slum-dwellers (first-order codes "high number of private providers" and "fragmented care pathway and high number of referrals to and from private providers").

\subsubsection{Affordability Matters}

Respondents' views on affordability issues were mixed. On the one side, affordability was perceived as a major obstacle in seeking good-quality healthcare. While some slum-dwellers forego healthcare treatment altogether to avoid catastrophic expenditures, others do seek care but rebound to government facilities, as private providers are considered unaffordable (first-order codes "unaffordable prices" and "private hospitals perceived as expensive").

Actually, we visited a government hospital. We can't afford to go to another hospital. (Soni)

So, the point is, we are considering to visit some other [private] hospital, but due to lack of money, we cannot really afford to go. (Meena)

Translator: And the same angioplasty, if she wants to do over there in the private hospital, they will charge INR Indian rupee) 50,000-80,000. The private hospital is for rich people.

Author: Did she ever consider to go to a private hospital?

Translator: She won't be able to afford so she didn't consider. Yeah, so they didn't. That's a waste of time to think about that because they won't afford it.

Also often times, pricing at private hospitals is unclear, and patients end up paying huge amounts, contrary to initial expectations (first-order codes "catastrophic expenditures" and "unclear pricing private hospitals"). For example, a respondent noted, 
For the consultancy he did, the doctor charged me INR 450 and he prescribed me a sonography. He charged INR 600. With the sonography they gave me, I went back to the Bhavanbai's place, and then he told me it's the appendix, I paid INR 12,000, filled up the form and I was operated. After the operation, there were lots of medicines and injections, and one injection was like INR 750, and then INR 1500 needed to be paid for the medicine, and everything. That has cost me around INR 25,000-30,000. (Preeti)

This is often accompanied by suspicions that private providers are mainly interested in profit rather than helping poor people (first-order code "mistrust for profit-oriented private facilities). It was noted by a respondent that,

The doctor charged INR 50,000 as a deposit, and then 5000 more for a medicine that he prescribed. And now I feel that they only wanted to fetch money from people like us. That's why he kept my father there for 10 days. Just to make more money. So, yeah, going there was a big mistake. (Rajesh)

Medical bills were reported to even exceed 100,000 INR (about $1250 €$ ) in some cases, while, in one case, it reached 300,000 INR (about $3750 €$ ). It emerged from several interviews that doctors are open to price negotiations with slum-dwellers, due to their affordability constraints (first-order codes "price negotiations"). While, on the one side, this is generally appreciated, some respondents noted that this practice has natural limits, because the patients are ultimately clients. One slum-dweller provided a particularly vivid description of this feeling,

From 30,000 rupees, the doctor reduced the price to 12,000 on humanitarian grounds, which is good of him. However, if a horse will do a friendship with the grass, how will he eat? If he shows more humanity to people, how much he will earn? So what is in his hand, he did the best for you but not more. (Preeti)

On the other side, many respondents also perceive affordability issues as not insurmountable, and secondary with respect to receiving good, life-saving healthcare (first-order code "low importance of price in decision-making"). Firstly, costs wereseen as unavoidable, because government hospitals do not deliver the necessary quality. One interviewee noted,

We changed to government hospital from Sola to VS, but even the problem wasn't cured, so it's better to go to the private. Even if it costs more, not an issue, we will go to the private. It's then that we decided to the Bhavanbai, who diagnosed properly that it was an appendix issue and not a blood clot. So he operated and the appendix was removed. (Preeti)

Another respondent observed,

It's not the question of the cheaper or higher prices, but when we don't get attended by the doctor, we don't get any consultancy or prescription or guidance, so what's the point going to the $\mathrm{CH}$ [civil hospital]. Even if it's cheaper, it doesn't make any sense, because they are not suggesting anything, they are not attending the patient. (Chandan)

Secondly, when compared with the prospect of losing a dear one, or one's own life, price becomes unimportant. Examples of this view are the following excerpts from our interviews:

They knew the DKH is a kidney special hospital and it's a good hospital, but first, they wanted to have a cheaper option, like $\mathrm{CH}$ or some other cheaper hospital, which they can afford. But finally, when they were not satisfied, they didn't want to risk their father's treatment and health. So they went to the private, now nothing is more important than their father. Money is not important. (Chandan)

... So she is saying the money is not important for me, my grandson is important for me. (Rupa)

It doesn't matter actually, the point is, I should recover, I should be treated, the money didn't make a difference. (Ramesh) 
When confronted with good-quality care and doctor's friendliness, prices seem reasonable (first-order code "reasonable price private facilities").

No, she didn't feel bad because, after seeing the treatment, she thought it's reasonable that he took 10,000-12,000 INR. This is a must for the treatment. And the doctor is really good, she is still appreciating his treatment. So she has recovered from the pain. She has a great respect for the doctor now. The doctor is really very nice. (Rita)

In addition to generally downplaying the importance of price in healthcare decisions, respondents also indicated a number of ways of coping with high health-related expenditures. Beyond the price negotiations highlighted above, private providers seem also open to other modes of payments, such as installments, foregone initial deposit, medical loans (albeit very expensive) (first-order codes "help from the community", "medical loans with high interests", and "suitable payment conditions"). What seems to be the most common practice is to receive monetary support from the community.

We paid in two installments because he stayed there for four days, so, on the first day, we paid some of the amounts, and then as the expenses were getting bigger and bigger, we recollected the money from neighbors and relatives, so we paid in two or three installments. (Rupa)

His daughter and his son had a little bit of money. So everyone contributed, from the community, everyone, neighbors, their friends. He wanted to mortgage his house, to save his father's life, but the community told him not to mortgage the house. They helped him in whatever way they could. (Sweta)

\section{Discussion}

\subsection{Hospital Choice and Its Drivers}

The quantitative study of this research revealed a significant difference between BOP and TOP patients in visits to public vs. private hospitals. This finding is in line with, among others, Peters et al. [34] and Howard and Roy [30], who found that BOP patients more often visited public hospitals than private hospitals. Overall, we found that most of the patients in our sample visited public hospitals, and that BOP patients visited public hospitals more than TOP patients. In evaluating these findings, however, it should be taken into account that our sample only included a small selection of private hospitals in Ahmedabad city and that the ratio of private to public hospital patients in our sample was 8.3:91.7.

We also found no significant difference between BOP and TOP in IP vs. OP treatments in hospitals. This finding suggests that BOP and TOP patients are similar in their choice of hospital depending on the type of treatment. This is contrary to the finding by Peters et al. [34], who reported that TOP patients took up a higher share in hospitalizations and, therefore, in inpatient services. This difference might be due to the characteristics of the private healthcare providers selected for this research vs. the research by Peters et al. [34]. The three private healthcare providers selected for this research were, in fact, all large hospitals (>100 beds), while Peters et al. [34] took the whole private hospital sector into account, including smaller clinics.

The findings from the qualitative study provided rich insight into the reasons for informants choosing a certain hospital. Social bonds, long-term relationships, and trust were identified by previous scholars as drivers for consumption choices at the BOP and as keys for the development of the BOP marketplace [1,38]. References were also mentioned by our informants as one of the main motivations to visit or not to visit a certain hospital. References and trustworthy information can indeed empower the BOP population to make better healthcare decisions. The acknowledgment of the importance of references, as well as of personal experience, as drivers of choice by BOP patients can be an incentive for hospitals to deliver good quality of care, to create and preserve a good reputation, to build a loyal customer base, and to engage into focused health promotion activities.

Several issues were found in the literature and in this study about the inadequacies of private and public hospital care in India [34]. Our findings add an important customer side to this issue by 
highlighting that, even when facilities are present, the perceptions of patients play an important role in shaping their hospital preferences. Further regulation, reforms, and development are needed to protect the population from failures in the healthcare sector. At the same time, successful business models for healthcare delivery at the BOP need to adopt co-creation approaches [26,27], which incorporate patients' insights, values, and beliefs early on as necessary starting points of the decisions on value propositions and value delivery mechanisms.

Absolute physical distance seemed to be of no importance to our informants in their selection of public vs. private hospitals. However, the distance was considered relevant in selecting a specific hospital within a type (public or private). Some informants motivated their choice of a specific hospital by explaining that the hospital was nearby, but it differed across participants with regards to the absolute distance of a nearby hospital. A possible explanation for the lower importance of physical distance from hospitals for our informants is the wide availability of hospitals in Ahmedabad city. There are six public hospitals in Ahmedabad [58] and a high number of private hospitals which are spread over the whole city, of which there are no reliable estimations.

In choosing a hospital or treatment, different types of decision-makers were identified. There were cases where the patients made their decision independently, and other, more numerous cases in which patients made their decision in collaboration with others. Sometimes, family members other than the patients were the final decision-makers. In these cases, our informants reported that these persons were senior family members, or were deemed to be more knowledgeable or educated. Contrary to the extant literature on consumer decision-making [40,72-74], this research found no clear influence of family makeup or gender roles on hospital or treatment choice. One possible reason for this is that decision-making in healthcare, especially in the BOP population, is different from the decision process to purchase goods and services. However, further research is needed on the role of different decision-makers to identify whether this factor is a major driver of choice in healthcare settings.

\subsection{Drivers for Choosing a Private Hospital}

Preference for private hospitals was given because of bad experiences with, or references for public hospitals. For some informants, the bad personal experience with public hospitals or discouragements by acquaintances outweighed the higher costs charged by private hospitals. Informants selected a private hospital as they were attended to promptly, got the right diagnosis, did not have too much paperwork before starting treatment, and received care from experienced and competent medical personnel. Furthermore, in private hospitals, they did not have to wait in long queues. Finally, private hospitals had the appropriate equipment. Many informants also indicated that costs were not of major importance. They explained they just wanted to regain health, and that public hospitals were distrusted or said to deliver low-quality care. These findings are in line with, among others, Klein [75] and Sengupta and Nundy [76], who argued that the motivation for BOP patients choosing private healthcare providers lay in that public providers lack facilities and quality. Deficiencies of public hospitals reported in previous studies include long waiting lines, filthy surroundings [76], poor management, low service quality, weak finances [34], inconvenient opening times, and lack of medicines [42], all of which also emerged from our interviews.

\subsection{Drivers for Choosing a Public Hospital}

Many informants reported that they had no other choice than to visit a public hospital, as they were unable to pay for their treatments in a private hospital. The two public hospitals considered in our study charged INR 5-10 for admission to the hospital, although additional charges were applied for certain specialty treatments. Another driver for visiting a public hospital was distrust in private hospitals. Misdiagnosis, overtreatment, wrong or inappropriate advice, lack of equipment, and unexpected excessive costs were mentioned as reasons for distrust in private hospitals. In these cases, public hospitals gained trust from our BOP informants. Similar issues on private hospitals were found in previous studies conducted in settings comparable to the one considered in our study, such as 
suspicion of conducting unnecessary and inappropriate medical procedures $[34,76]$, prescription of unnecessary drugs [77], and working without standards of care and with unqualified practitioners [34]. This evidence does not mean that all private hospitals lack facilities, but does indicate a possible policy and implementation gap in regulation in healthcare. There is a lack of government regulations, for example, on quality standards of care [34], licensing, and accreditation. Furthermore, regulatory failures contribute to high corruption [42]. It was found that the private providers used by the BOP population tends to be different from those used by TOP counterparts, and often employ less qualified practitioners $[29,34]$. Overall, several factors that make the BOP population more vulnerable in their choice of healthcare providers underscore the importance of careful regulation of the private healthcare sector $[29,34,42]$.

\subsection{A Grounded Theory Model of Private Healthcare Provider Choice: The Role of Aspirational Demand}

Our interviewees revealed a strong inclination toward the choice of private providers, through what emerges as BOP patients' "aspirational demand". We introduce this concept in close connection with the consumer marketing literature related to "aspirational brands", i.e., brands that are strongly desired by a large audience, although only a small fraction can afford them [78]. In the context of BOP communities, aspirational demand refers to the consumers' wish to own a product that is associated with higher quality, higher utility, or higher prestige/status, but that cannot be appropriated because of financial constraints.

Aspirational demand for private services emerges throughout our three main themes. When looking at healthcare-seeking as a socio-cultural process, respondents noted that they are inclined toward choosing private providers not only given their own positive experience, but also following opinions and suggestions of the community at large. The general positive aura surrounding private healthcare providers resulted from the good relationships that individuals and communities established with doctors over time, because of the personal connections with doctors or medical staff working in private facilities, and because doctors seemed to be attuned with the need of the local people, in terms of emotional support and friendliness.

This feeling co-evolves with the second main theme, namely the perceived higher quality of private providers. In addition to friendliness and the possibility to establish trust-based relationships with private providers, the respondents strongly pointed out the higher service levels offered by private hospitals, which manifests in shorter waiting times and more accurate diagnoses and treatments. Moreover, experiencing private healthcare provision is associated with status and prestige, as noted by the respondents who highlighted receiving customized assistance, or enjoying a TV or a clean room, as a luxury moment for them. Therefore, private providers display both the quality levels and the socio-cultural acceptability to be BOP patients' preferred choice. Moreover, a high number of private providers are present within and around slum communities in the selected setting, such that distance and transportation did not emerge as an important determinant of provider choice.

In view of these aspects, affordability surfaces as the one major constraint that hinders BOP patients' use of private facilities. However, although high prices and the risk of catastrophic healthcare expenditures play a major role in the choice of healthcare provider by BOP patients, the relative importance of these aspects was somewhat downplayed by several respondents, who depicted price as a secondary dimension with respect to health-related matters. Thus, even in considering financial aspects, the perception is ambivalent. While some interviewees clearly recognized the unaffordability of private healthcare and even advanced suspicions toward the good intentions and honesty of private providers, others underlined that prices are fair and there is the possibility to rely on the help of other community members and on favorable payment conditions, such as discounts offered by humanitarian doctors or installments. Thus, although affordability, in general, discourages the use of private healthcare services, there are some conflicting internal dynamics.

The observations above led to a dynamic grounded theory of BOP healthcare preference for private providers, which is represented in Figure 2. Here, the nine second-order codes are grouped 
into the three main aggregate themes. The model also includes the latent construct of aspirational demand and its positive influence on the choice of a private healthcare provider. Plus and minus signs highlight the expected positive or negative influence the variables exert on each other. Noteworthy is the internal dynamics created by the positive or negative effects of the second-order variables on each other. For example, while "affordability issues related to private providers" negatively influence the choice of private hospitals, the remaining two sub-constructs composing the aggregate construct "affordability matters", i.e., "variety of payment possibilities" and "price as a secondary dimension with respect to health", are expected to mitigate perceived affordability issues, leading to their negative impact on the preference for private providers.

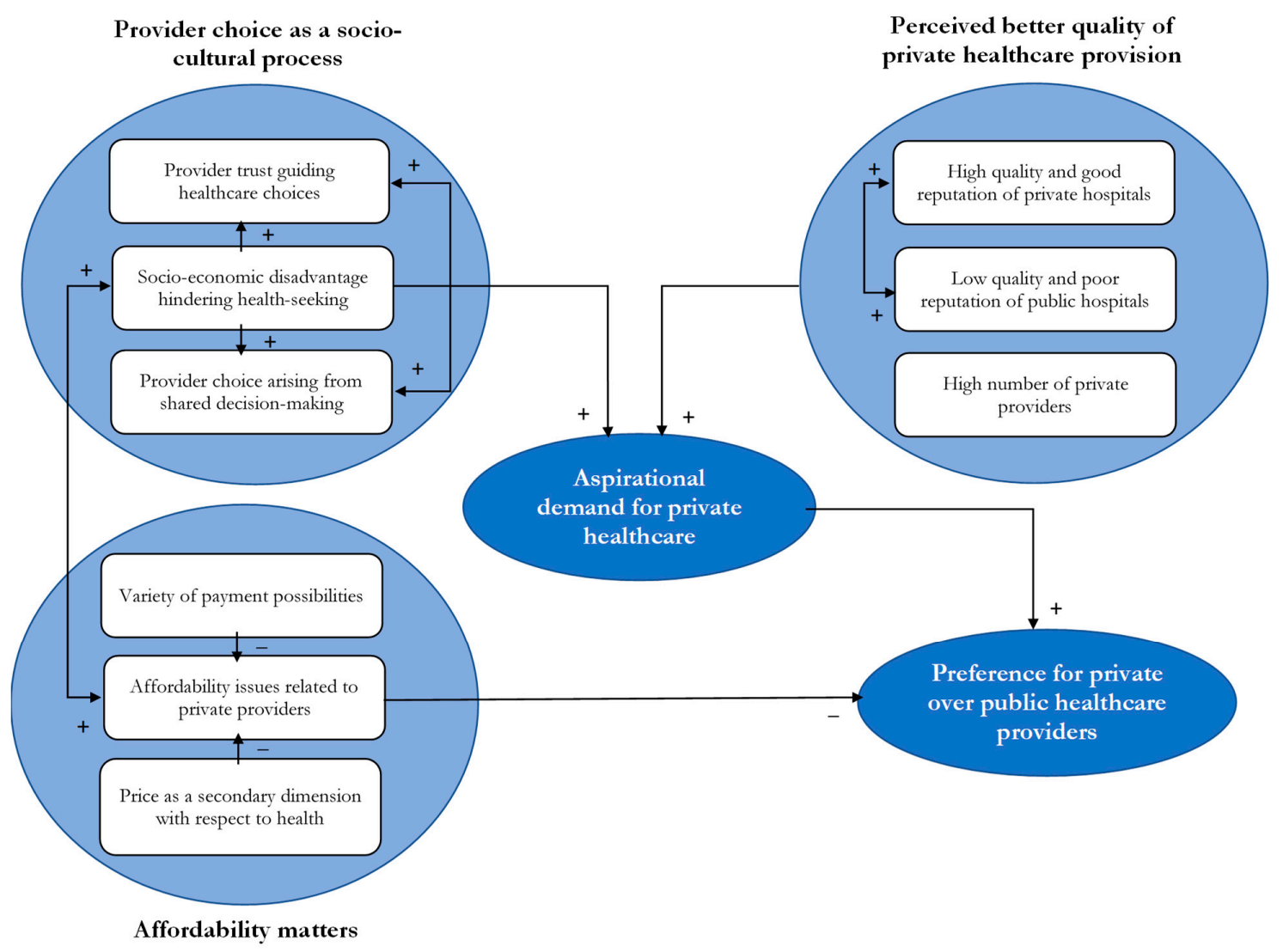

Figure 2. A grounded theory model of private healthcare choice.

\section{Contribution, Implications, and Limitations}

\subsection{Contributions and Implications}

We make several contributions to the extant literature. Our research responds to the need for systematic research on the BOP healthcare market, which is due to the large unmet demand for healthcare services, especially in the Indian context $[15,33]$. Although previous studies quantitatively investigated the factors affecting the choice of healthcare providers by BOP consumers [28], these studies primarily focused on attributes affecting the choice of healthcare providers in general. To the best of our knowledge, no study so far unveiled the decision-making process underlying the choice of healthcare providers, especially with regards to the choice of public vs. private hospitals. In taking up this challenge, the present paper contributes toward a better understanding of the complex interplay of socio-cultural and socio-economic dimensions underpinning BOP consumers' preference of healthcare providers.

Furthermore, whereas prior studies in BOP literature discussed business model innovations implemented by various organizations to deliver inclusive healthcare [23,35], there is a paucity of 
research discussing healthcare providers in BOP settings from the perspective adopted in the present study, i.e., from the customers' perspective. This perspective can enhance our understanding of the needs and perceptions of BOP consumers and, thus, facilitate the co-creation of consumer-centric and socio-culturally sensitive business models for healthcare delivery. While the development and implementation of such business models will benefit from the organizational capabilities accumulated over time by those healthcare providers who are more accustomed to deal with cross-cultural differences [79], a distinctive contribution of our study is that of uncovering the aspirational demands of BOP consumers in the healthcare domain. Our fieldwork showed indeed that BOP consumers aspire to select healthcare providers who can offer high-quality services and also, in some respect, to enhance their social standing, although they often cannot afford the private health services owing to their living conditions and severe budgetary constraints.

Our finding that BOP patients prefer private over public healthcare, despite the downsides of high costs and, at times, sub-optimal quality, has managerial and policy implications. The choice of public hospitals has indeed the potential to push BOP households further below the poverty line. Our research highlights the need for public healthcare providers to improve the perceived quality of their services and, in general, to better attract BOP patients to more affordable healthcare providers. Our study also suggests the need for a third set of healthcare enterprises apart from traditional for-profit private providers and public providers. This third category consists of healthcare social enterprises such as Aravind Eye Hospital in India [35]. While being private organizations, these social enterprises are driven toward the social mission of providing low-cost quality healthcare, and they leverage substantial business model innovation to dramatically reduce costs and to generate enough economic resources to ensure financial sustainability.

Another major implication of our work is that it may be inappropriate to view the BOP population as one homogeneous group requiring the same treatments. Previous studies highlighted that the BOP markets are composed of multiple segments based on the relative economic conditions of people [80,81]. Those residing in the middle or lower-middle part of the economic pyramid can avail private healthcare services if these are made affordable and inclusive. However, those who constitute the real "bottom" of the pyramid and, as such, live in extreme poverty would surely be dependent on public healthcare. This aspect accentuates the need for higher government spending on healthcare and improvement in public healthcare infrastructure. Further efforts are needed to improve access to healthcare by means of government medical insurance schemes such as the Ayushman Bharat health scheme, the world's largest government-funded healthcare scheme recently launched by the Indian government in Ranchi, the capital of Jharkhand state [82].

The present study also speaks to those interested in the role played by social networks for the governance of economic activity. We found that interpersonal ties and trust-based relationships between patients and doctors, and the need for healthcare providers to preserve their reputation in closely knit communities, wherein information on the competencies and trustworthiness of individuals and organizations circulate rapidly, all act as "social mechanisms" [83] that facilitate coordination between patients and healthcare providers. While these mechanisms and their effectiveness are grounded into the embeddedness of economic activity in complex networks of social relationships, previous research argued that these mechanisms, and the overall processes of network governance are amenable to purposeful management $[84,85]$. Accordingly, a major managerial implication of our study is that healthcare providers should incorporate these mechanisms early on into their own business models, and learn over time how to leverage them in order to improve their ability to satisfy their customers' needs and, thus, their own economic performance and ability to compete.

Finally, our study has significant implications for the literature on sustainability in healthcare. To maximize the social impact on the community and to effectively contribute to poverty alleviation and local development, healthcare business models need to be profoundly aware of the affordability needs of the targeted populations and of the importance of the community as a whole in the health-related decision-making process of single individuals. Thus, familiarity with doctors, trust, 
favorable payment conditions, and fast and preferably outpatient treatments should be emphasized in future business models.

\subsection{Limitations and Directions for Future Research}

The present study is not without its limitations, however. Firstly, being based on a sample of six hospitals in a single Indian city, our study may not necessarily provide a complete overview of patient behavior regarding the selection of private vs. public hospitals in lower-middle-income countries. Future studies can examine the patient choice behavior across multiple cities to generate better countrywide insights into patient behavior. Another limitation of our quantitative study lies in that the selected hospitals used different formats to collect patient data, such that merging datasets from different hospitals resulted in the loss of data. In addition to that, since the patient data are registered manually at the hospitals, errors in the registration may have occurred. Finally, the selection of the residential areas that are representative of the BOP and TOP populations was based on the last comprehensive statistical report available for Ahmedabad city, which dates back to 2007. Nevertheless, based on information gained from the inhabitants, we are confident that the socio-economic composition of the selected areas did not radically change since then.

The current study examined the behavior of people living in urban slum areas. Future researchers can examine the differences between low-income patients living in rural and urban areas. Unlike their urban counterparts, consumers living in rural areas have far lower exposure to media, present a lower level of health literacy, and have lower accessibility to health facilities, due to poor road connectivity, telecom infrastructure, and electricity. Furthermore, the presence of quality private hospitals in rural areas is lower as they more commonly provide tertiary care in large cities [50]. It will be interesting to investigate rural patients' perception of unqualified and untrained doctors, known as quacks, who commonly operate in rural areas.

Additionally, it will be interesting to examine patient behavior across different therapeutic areas such as critical care, hematology and oncology, cardiovascular study, and immunology. Patient behavior is likely to be different across acute therapeutic areas such as cardiovascular diseases than chronic areas, e.g., diabetes, where rural patients delay the treatment owing to lack of awareness of their ailments. In August 2018, the Government of India launched Ayushman Bharat National Health Protection Mission that caters to more than 100 million deprived households and provides coverage of up to 0.5 million INR per household each year for secondary and tertiary care [56]. Future research can examine how this scheme affects the perception of low-income consumers toward private hospitals with, for example, quasi-experimental studies.

\section{Conclusions}

This article aimed at unveiling the determinants of BOP patient choice of public vs. private hospitals in an Indian slum setting, in an attempt to investigate the socio-cultural acceptability of current models of private healthcare delivery. Through a mixed-method research approach, the evidence produced a complex picture of BOP patient preferences and health-seeking behavior. Our quantitative findings indicate that BOP patients visit public hospitals significantly more often than wealthier individuals, regardless of the type of treatment sought (inpatient or outpatient care), and our qualitative results provide insights into why BOP patients refer most often to public providers. However, the qualitative findings also powerfully highlight a strong aspirational demand of BOP patients for private healthcare services, which appear to be of high perceived value, highly socio-culturally attuned to the needs of the BOP community, and easily available in terms of number and reach. This perception seems strongly entrenched within the BOP community and in co-evolution with the very low reputation associated with public hospitals. Although cheap if not free, government services are perceived by BOP consumers as untrustworthy or poor quality, and generally unsuited to their needs. A clear discrepancy, thus, emerges between our quantitative and qualitative findings, which can be reconciled through the concept of aspirational demand. Although 
private providers are associated with higher status and attributed higher quality and socio-cultural adherence to BOP patient needs, affordability aspects hinder consumers from choosing private healthcare provision. This resulted in a significantly higher frequency of visits of BOP patients to public hospitals that emerged from the analysis of our quantitative data.

Author Contributions: Conceptualization, F.A., S.T.I. and A.K.J.; methodology, F.A., S.T.I., A.K.J. and A.C.; formal analysis, F.A., S.T.I.; investigation, S.T.I.; data curation, S.T.I., F.A.; writing-original draft preparation, F.A., S.T.I., A.K.J. and A.C.; writing-review and editing, F.A., S.T.I., A.K.J. and A.C.

Funding: This research received no external funding. The APC was funded by Tilburg School of Social and Behavioral Sciences.

Acknowledgments: The authors would like to sincerely thank all the study participants. The authors are also thankful to Dhiman Bhadra of IIM Ahmedabad for his input in the statistical analysis.

Ethical Considerations: Before the interviews, all respondents were provided with details about the purpose of the study and their expected contribution to the research. Participation was entirely voluntary. Signed written informed consent was collected, in which the respondents agreed to participate, to have their interview tape-recorded, and to the have their personal information used in the final report. Nevertheless, to further ensure personal data protection, the respondents' names were pseudonymized. The study obtained the ethical approval number IIMA IRB 201802 by the Institutional Ethical Review Board of the Indian Institute of Management, Ahmedabad.

Conflicts of Interest: The authors declare no conflicts of interest.

\section{Abbreviation List}

$\begin{array}{ll}\text { BOP } & \text { Bottom of the pyramid } \\ \text { IBEF } & \text { Indian Brand Equity Foundation } \\ \text { IMR } & \text { Infant mortality rate } \\ \text { IP } & \text { Inpatient } \\ \text { OP } & \text { Outpatient } \\ \text { SDG } & \text { Sustainable development goal } \\ \text { TBL } & \text { Triple bottom line } \\ \text { TOP } & \text { Top of the pyramid } \\ \text { U5MR } & \text { Under-five mortality rate } \\ \text { UNDP } & \text { United Nations Development Program } \\ \text { WHO } & \text { World Health Organization }\end{array}$

\section{References}

1. Prahalad, C.K. The Fortune at the Bottom of the Pyramid: Eradicating Poverty through Profits; Pearson Prentice Hall: Upper Saddle River, NJ, USA, 2006.

2. Prahalad, C.K.; Hart, S.L. The Fortune at the Bottom of the Pyramid. Strategy Mag. 2002, 273, 99-111. [CrossRef]

3. Khalid, U.; Seuring, S. Analyzing Base-of-the-Pyramid Research from a (Sustainable) Supply Chain Perspective. Available online: https:/ / doi.org/10.1007/s10551-017-3474-x (accessed on 10 December 2018).

4. Kolk, A.; Rivera-Santos, M.; Rufin, C. Reviewing a Decade of Research on the "Base/Bottom of the Pyramid" (BOP) Concept. Bus. Soc. 2014, 53, 338-377. [CrossRef]

5. Arnold, D.G.; Valentin, A. Corporate social responsibility at the base of the pyramid. J. Bus. Res. 2013, 66, 1904-1914. [CrossRef]

6. Arnold, D.G.; Williams, L.H.D. The paradox at the base of the pyramid: Environmental sustainability and market-based poverty alleviation. Int. J. Technol. Manag. 2012, 60, 44-59. [CrossRef]

7. Hammond, A.; Kramer, W.J.; Katz, R.S.; Tran, J.T.; Walker, C. The Next 4 Billion: Market Size and Business Strategy at the Base of the Pyramid; World Resources Institute and International Finance Corporation/World Bank Group: Washington, DC, USA, 2007.

8. George, G.; Howard-Grenville, J.; Joshi, A.; Tihanyi, L. Understanding and tackling societal grand challenges through management research. Acad. Manag. J. 2016, 59, 1880-1895. [CrossRef] 
9. Elkington, J. Cannibals with Forks, the Triple Bottom Line of 21 Century Business; Kluwer Academic Publishers: Dordrecht, The Netherlands, 1997.

10. Hussain, N.; Rigoni, U.; Orij, R.P. Corporate Governance and Sustainability Performance: Analysis of Triple Bottom Line Performance. J. Bus. Ethics 2018, 149, 411-432. [CrossRef]

11. Svensson, G.; Høgevold, N.; Ferro, C.; Varela, J.C.; Padin, C.; Wagner, B. A Triple Bottom Line Dominant Logic for Business Sustainability: Framework and Empirical Findings. J. Bus. Bus. Mark. 2016, 23, 153-188. [CrossRef]

12. Reid, D. Sustainable Development: An Introductory Guide; Earthscan: Abingdon-on-Thames, UK, 1995.

13. WHO. WHOI Poverty and Health; World Health Organ; WHO: Geneva, Switzerland, 2016.

14. UNDP. Barriers and Opportunities at the Base of the Pyramid-The Role of the Private Sector in Inclusive Development; UDNP: New York, NY, USA, 2014.

15. Wagstaff, A. Poverty and health sector inequalities. Bull. World Health Organ. 2002, 80, 97-105. [PubMed]

16. Government of India. Draft National Health Policy 2015; Ministry of Health and Family Welfare: New Delhi, India, 2014.

17. Bhatnagar, N.; Grover, M. Health care for the "bottom of the pyramid". Popul. Health Manag. 2014, 17, 5-7. [CrossRef] [PubMed]

18. Yunus, M.; Moingeon, B.; Lehmann-Ortega, L. Building social business models: Lessons from the grameen experience. Long Range Plan. 2010, 43, 308-325. [CrossRef]

19. Das, M.; Angeli, F.; Krumeich, A.J.S.M.; Van Schayck, O.C.P. Patterns of illness disclosure among Indian slum dwellers: A qualitative study. BMC Int. Health Hum. Rights 2018, 18, 3. [CrossRef] [PubMed]

20. Das, M.; Angeli, F.; Krumeich, A.J.S.M.; Van Schayck, O.C.P. The gendered experience with respect to health-seeking behaviour in an urban slum of Kolkata, India. Int. J. Equity Health 2018, 17, 24. [CrossRef] [PubMed]

21. Angeli, F.; Jaiswal, A.K. Competitive Dynamics between MNCs and Domestic Companies at the Base of the Pyramid: An Institutional Perspective. Long Range Plan. 2015, 48, 182-199. [CrossRef]

22. Rivera-Santos, M.; Rufín, C. Global village vs. small town: Understanding networks at the Base of the Pyramid. Int. Bus. Rev. 2010, 19, 126-139. [CrossRef]

23. Angeli, F.; Jaiswal, A.K. Business Model Innovation for Inclusive Health Care Delivery at the Bottom of the Pyramid. Organ. Environ. 2016, 29, 486-507. [CrossRef]

24. Bhattacharyya, O.; Khor, S.; McGahan, A.; Dunne, D.; Daar, A.S.; Singer, P.A. Innovative health service delivery models in low and middle income countries-What can we learn from the private sector? Health Res. Policy Syst. 2010, 8, 24. [CrossRef] [PubMed]

25. Marmot, M.; Friel, S.; Bell, R.; Houweling, T.A.; Taylor, S. Closing the gap in a generation: Health equity through action on the social determinants of health. Lancet 2008, 372, 1661-1669. [CrossRef]

26. Alexy, O.; George, G. Category Divergence, Straddling, and Currency: Open Innovation and the Legitimation of Illegitimate Categories. J. Manag. Stud. 2013, 50, 173-203. [CrossRef]

27. George, G.; Rao-Nicholson, R.; Corbishley, C.; Bansal, R. Institutional entrepreneurship, governance, and poverty: Insights from emergency medical response servicesin India. Asia Pac. J. Manag. 2015, 32, 39-65. [CrossRef]

28. Černauskas, V.; Angeli, F.; Jaiswal, A.K.; Pavlova, M. Underlying determinants of health provider choice in urban slums: Results from a discrete choice experiment in Ahmedabad, India. BMC Health Serv. Res. 2018, 18, 473. [CrossRef]

29. Gangolli, L.V.; Duggal, R.; Shukla, A. Review of Healthcare in India; Centre for Enquiry into Health and Allied Themes: Mumbai, India, 2005.

30. Howard, D.H.; Roy, K. Private Care and Public Health: Do Vaccination and Prenatal Care Rates Differ between Users of Private versus Public Sector Care in India? Health Serv. Res. 2004, 39, 2013-2026. [CrossRef] [PubMed]

31. World Bank. Landscape of Inclusive Business Models of Healthcare in India Business Model Innovations; The World Bank: Washington, DC, USA, 2014.

32. WHO; NHA Indicators. Glob. Health Expend. Database; WHO: Geneva, Switzerland, 2014. 
33. IBEF. Healthcare Industry in India, Indian Healthcare Sector Services; IBEF: New Delhi, India, 2018.

34. Peters, D.H.; Yazbeck, A.S.; Sharma, R.R.; Ramana, G.N.; Pritchett, L.H.; Wagstaff, A. Better Health Systems for India's Poor; The World Bank: Washington, DC, USA, 2002.

35. Rangan, V.K.; Thulasiraj, R.D. Making Sight Affordable. Innovations Case Narrative: The Aravind Eye Care System; MIT Press: Cambridge, MA, USA, 2007.

36. Subrahmanyan, S.; Gomez-Arias, J.T. Integrated approach to understanding consumer behavior at bottom of pyramid. J. Consum. Mark. 2008, 25, 402-412. [CrossRef]

37. Mahal, A.; Yazbeck, A.S.; Peters, D.H.; Ramana, G.N.V. The Poor and Health Services Use in India; The World Bank: Washington, DC, USA, 2001.

38. Kuo, T.; Hanafi, J.; Sun, W.; Robielos, R. The Effects of National Cultural Traits on BOP Consumer Behavior. Sustainability 2016, 8, 272. [CrossRef]

39. Chakravarti, D. Voices Unheard: The Psychology of Consumption in Poverty and Development. J. Consum. Psychol. 2006, 16, 363-376. [CrossRef]

40. Chikweche, T.; Stanton, J.; Fletcher, R. Family purchase decision making at the bottom of the pyramid. J. Consum. Mark. 2012, 29, 202-213. [CrossRef]

41. Dawar, N.D.N.; Chattopadhyay, A. Rethinking Marketing Programs for Emerging Markets. Long Range Plan. 2002, 35, 457-474. [CrossRef]

42. Radwan, I. India: Private Health Services for the Poor; The World Bank: Washington, DC, USA, 2005.

43. Arora, S.; Romijn, H. The empty rhetoric of poverty reduction at the base of the pyramid. Organization 2012, 19, 481-505. [CrossRef]

44. Karnani, A. The Mirage of Marketing to the Bottom of the Pyramid. Calif. Manag. Rev. 2007, 49, 90-111.

45. Walsh, J.P.; Kress, J.C.; Beyerchen, K.W. Promises and perils at the bottom of the pyramid. Adm. Sci. Q. 2005, 50, 473-482. [CrossRef]

46. Simanis, E.; Hart, S.; Duke, D. The Base of the Pyramid Protocol: Beyond "Basic Needs" Business Strategies. Innov. Technol. Gov. Glob. 2008, 3, 57-84. [CrossRef]

47. Sachs, W. The Development Dictionary: A Guide to Knowledge as Power; Zed Books: London, UK; New York, NY, USA, 1992.

48. Simanis, E.; Hart, S. The Base of the Pyramid Protocol: Toward Next Generation BoP Strategy. Innov. Technol. Gov. Glob. 2008, 2, 1-57.

49. Sen, A. Development Freedom; Anchor Books: New York, NY, USA, 1999.

50. India Brand Equity Foundation, Healthcare Industry in India; IBEF: New Delhi, India, 2018.

51. World Bank. The World Bank Data: Health; The World Bank Open Data: Washington, DC, USA, 2018.

52. Rao, N. Who Is Paying for India's Healthcare? Available online: https://thewire.in/health/who-is-payingfor-indias-healthcare (accessed on 10 December 2018).

53. National Institute for Transforming India. Health Index, Transforming States to Transform India. Available online: http:/ / social.niti.gov.in/uploads/sample/health_index_report.pdf (accessed on 10 December 2018).

54. Kurian, O.C. Gujarat: Economically Upfront, but Far behind in Health. Available online: https:/ / www.orfonline.org/expert-speak/gujarat-economically-upfront-far-behind-health/ (accessed on 10 December 2018).

55. Jegede, A. Top 10 Largest Hospitals in the World. Available online: https://www.trendrr.net/3980/bestlargest-hospitals-world-cancer-famous-luxurious-expensive/ (accessed on 10 December 2018).

56. Government of India. Ninety-Ninth Report, Demands for Grants 2017-2018 (Demand No. 42). Available online: http://164.100.47.5/newcommittee/reports/EnglishCommittees/ CommitteeonHealthandFamilyWelfare/99.pdf (accessed on 10 December 2018).

57. Roy, S.; Katoti, R.G.; Tata Services Ltd. Department of Economics and Statistics. In Statistical outline of India, 2006-2007; Tata Services: Mumbai, India, 2007.

58. Government of Gujarat. District wise Government Hospitals. Available online: http:/ /www.magujarat. com/DistrictwiseHospitalEmpanelment.html (accessed on 10 December 2018).

59. Polit, D.F.; Beck, C.T. Nursing Research: Generating and Assessing Evidence for Nursing Practice; Lippincott Williams \& Wilkins: Philadelphia, PA, USA, 2008. 
60. Foley, G.; Timonen, V. Using grounded theory method to capture and analyze health care experiences. Health Serv. Res. 2015, 50, 1195-1210. [CrossRef] [PubMed]

61. Elsey, H.; Manandah, S.; Sah, D.; Khanal, S.; MacGuire, F.; King, R.; Wallace, H.; Baral, S.C. Public health risks in urban slums: Findings of the qualitative "healthy kitchens healthy cities" study in Kathmandu, Nepal. PLoS ONE 2016, 11, e0163798. [CrossRef] [PubMed]

62. Beech, R.; Henderson, C.; Ashby, S.; Dickinson, A.; Sheaff, R.; Windle, K.; Wistow, G.; Knapp, M. Does integrated governance lead to integrated patient care? Findings from the innovation forum. Health Soc. Care Commun. 2013, 21, 598-605. [CrossRef] [PubMed]

63. Bain, N.S. Treating patients with colorectal cancer in rural and urban areas: A qualitative study of the patients' perspective. Fam. Pract. 2000, 17, 475-479. [CrossRef] [PubMed]

64. Flink, M.; Öhlén, G.; Hansagi, H.; Barach, P.; Olsson, M. Beliefs and experiences can influence patient participation in handover between primary and secondary care-A qualitative study of patient perspectives. BMJ Qual. Saf. 2012, 21 (Suppl. 1), 76-83. [CrossRef]

65. Goudet, S.M.; Kimani-Murage, E.W.; Wekesah, F.; Wanjohi, M.; Griffiths, P.L.; Bogin, B.; Madise, N.J. How does poverty affect children's nutritional status in Nairobi slums? A qualitative study of the root causes of undernutrition. Public Health Nutr. 2017, 20, 609-618. [CrossRef] [PubMed]

66. Clarke, V.; Braun, V. Teaching thematic analysis: Over- coming challenges and developing strategies for effective learning. Psychologist 2013, 26, 120-123.

67. Ritchie, J.; Lewis, J.; McNaughton Nicholls, C.; Ormston, R. Qualitative Research Practice: A Guide for Social Science Students and Researchers; SAGE: Thousand Oaks, CA, USA, 2014.

68. Gioia, D.A.; Corley, K.G.; Hamilton, A.L. Seeking Qualitative Rigor in Inductive Research: Notes on the Gioia Methodology. Organ. Res. Methods 2013, 16, 15-31. [CrossRef]

69. Corbin, J.M.; Strauss, A. Grounded theory research: Procedures, canons, and evaluative criteria. Qual. Sociol. 1990, 13, 3-21. [CrossRef]

70. Strauss, A.L.; Corbin, J.M. Basics of Qualitative Research: Techniques and Procedures for Developing Grounded Theory; SAGE: Thousand Oaks, CA, USA, 1998.

71. Gruiskens, J.; Ormiston, J.; Angeli, F.; Van Schayck, O.C. The antecedents of healthcare social entrepreneurship. In Healthcare Entrepreneurship; Wilden, R., Garbuio, M., Angeli, F., Mascia, D., Eds.; Routledge, Taylor \& Francis Group: Abingdon, UK, 2018; pp. 221-258.

72. Burns, D.J. Husband-wife innovative consumer decision making: Exploring the effect of family power. Psychol. Mark. 1992, 9, 175-189. [CrossRef]

73. Lackman, C.; Lanasa, J.M. Family decision-making theory: An overview and assessment. Psychol. Mark. 1993, 10, 81-93. [CrossRef]

74. Su, C.; Fern, E.F.; Ye, K. A Temporal Dynamic Model of Spousal Family Purchase-Decision Behavior. J. Mark. Res. 2003, 40, 268-281. [CrossRef]

75. Klein, T. Why do India's Urban Poor Choose to Go Private? Health Policy Simulations in Slums of Hyderabad; Ibidem-Verl: Stuttgart, Germany, 2012.

76. Sengupta, A.; Nundy, S. The private health sector in India. BMJ 2005, 331, 1157-1158. [CrossRef] [PubMed]

77. Das, J.; Hammer, J. Money for nothing: The dire straits of medical practice in Delhi, India. J. Dev. Econ. 2007, 83, 1-36. [CrossRef]

78. Trocchia, P.J.; Saine, R.Q.; Luckett, M.G. I've wanted a BMW since I was a kid: An exploratory analysis of the aspirational brand. J. Appl. Bus. Res. 2015, 31, 331-344. [CrossRef]

79. Capaldo, A.; Della Piana, B.; Vecchi, A. Managing Across Cultures in a Globalized World. Findings from a Systematic Literature Review. Glob. Commun. 2012, 1, 7-40.

80. Jaiswal, A.K. The Fortune at the Bottom or the Middle of the Pyramid? Innov. Technol. Gov. Glob. 2008, 3 , 85-100. [CrossRef]

81. Rangan, K.V.; Chu, M.; Petkoski, D. Segmenting the Base of the Pyramid. Harv. Bus. Rev. 2011, 89, $113-117$.

82. Economic Times India. Ayushman Bharat Health Insurance Scheme: Who All It covers and How $\mid$ Ayushman Bharat Scheme Complete Guide. Available online: https://economictimes.indiatimes.com/wealth/ insure/ayushman-bharat-how-to-check-entitlement-and-eligibility/articleshow / 65422257.cms (accessed on 10 December 2018).

83. Capaldo, A. Network governance: A cross-level study of social mechanisms, knowledge benefits, and strategic outcomes in joint-design alliances. Ind. Mark. Manag. 2014, 43, 685-703. [CrossRef] 
84. Capaldo, A. Network structure and innovation: The leveraging of a dual network as a distinctive relational capability. Strategy Manag. J. 2007, 28, 585-608. [CrossRef]

85. Capaldo, A.; Giannoccaro, I. How does trust affect performance in the supply chain? the moderating role of interdependence. Int. J. Prod. Econ. 2015, 166, 36-49. [CrossRef]

(C) 2018 by the authors. Licensee MDPI, Basel, Switzerland. This article is an open access article distributed under the terms and conditions of the Creative Commons Attribution (CC BY) license (http:/ / creativecommons.org/licenses/by/4.0/). 